\title{
Sparking Creativity with Robots: A Design Perspective
}

\author{
Patrícia Alves-Oliveira \\ Dept. of Psychology \\ ISCTE-IUL - CIS-IUL - INESC-ID \\ Lisbon, Portugal \\ patricia_alves_olivera@iscte-iul.pt \\ Ramona Merhej \\ Dept. of Computer Science \\ Instituto Superior Técnico - INESC-ID \\ Lisbon, Portugal \\ ramona.merhej@gaips.inesc-id.pt
}

\author{
Silvia Tulli \\ Dept. of Computer Science \\ Lisbon, Portugal \\ silvia.tulli@gaips.inesc-id.pt \\ João Gandum \\ Dept. of Computer Science \\ Instituto Superior Técnico \\ Lisbon, Portugal \\ joao.gandum@tecnico.ulisboa.pt
}

Instituto Superior Técnico - INESC-ID

\author{
Philipp Wilken \\ Dept. of Business Informatics \\ University Duisburg-Essen \\ Duisburg-Essen, Germany \\ philipp.wilken@stud.uni-due.de
}

\author{
Ana Paiva \\ Dept. of Computer Science \\ Instituto Superior Técnico - INESC-ID \\ Lisbon, Portugal \\ ana.paiva@inesc-id.pt
}

\begin{abstract}
We present the design and evaluation process of a robot aimed at stimulating creativity in humans in a drawingoriented collaborative drawing task. Collaboration towards a common goal is known to be one of the most influential factors for creativity nourishing. The social robot acted as a collaborative peer in a drawing activity, taking turns with the human, to complete their drawing. In each turn, both "artists" (the robot and the human) draw something new until they achieved their final drawing. The goal was to study if a robot, in comparison with a tablet, can stimulate creativity. A total of 28 participants were distributed across robot and tablet conditions. Creativity scores for each drawing were calculated. Contrary to what was expected, creativity score did not present statistically significant main effect across conditions. We discuss our results under a design perspective, addressing the role of the robot's embodiment and presence, as well as the purpose of use for robots in society and what implications there is for design.
\end{abstract}

Index Terms-Social robots, co-creativity, critical design, speculative design, embodiment

\section{INTRODUCTION}

Creativity is one of the most sought-after skills with major implications for well-being and personal life, and it is related to career professional success in career [1]-[3]. The role of creativity in society has been highlighted and valued [4]. As a consequence, developed societies have put emphasis on the value of innovation, collaboration, and creative problem solving, over standardized knowledge [5]. Therefore, the economy of developed societies is shifting from an industrial economy, that valued manufacturing work and standard memorization of procedures, towards a creative economy, valuing creativity at work [6]-[8]. Knowing this, it becomes imperative to study and develop ways to spark creativity, specially using new technologies, such as social robots.

Scholars have been debating about how to harnesses the creative potential. On the one hand, changes in the traditional school system have been suggested, namely concerning curriculum content, teaching approaches, and education for empowerment [9]. Other developments have been made targeting adults and the workplace, specifically by studying which work environment characteristics stimulate creativity [10], how communication and the quality of the relationship affects creativity [11], and other additional conditions related with creativity nourishing, such as independence and the nature of the task itself [12]. From these variables that influence creativity development, collaboration (or teamwork), defined by a group of people working together towards a common goal by interacting with each other, is known to be one of the most influential factors [13].

In this work, we designed and developed a collaborative activity between a social robot and a human participant to understand the effects of human-robot interaction (HRI) on creativity outcomes. The team was constituted by one humanoid robot and one adult participant that engaged in an open-ended collaborative drawing task. This meant that the "artists" (study participants and the robot) could draw anything. The resulting product, i.e., their final drawing, was evaluated in terms of creativity scores. We compared the results with a control condition constituted by a tablet to investigate the effects of the robot's embodiment and presence on creativity.

\section{RELATED WORK}

\section{A. Defining Creativity}

Creativity is considered one of the highest human cognitive abilities [22]. It is a multi-faced concept with over 60 different definitions in the field of psychology alone [23], [24]. While earliest definitions of creativity described this ability as a function of an individual [14], creativity definition has evolved and is now defined as an interaction between aptitude, environment, and process by which an individual or a group produces a tangible product that is both novel and useful, within the social context [25]. More definitions are present in 
TABLE I

SUMMARY OF SELECTED DEFINITIONS OF CREATIVITY IN TIMELINE ORDER.

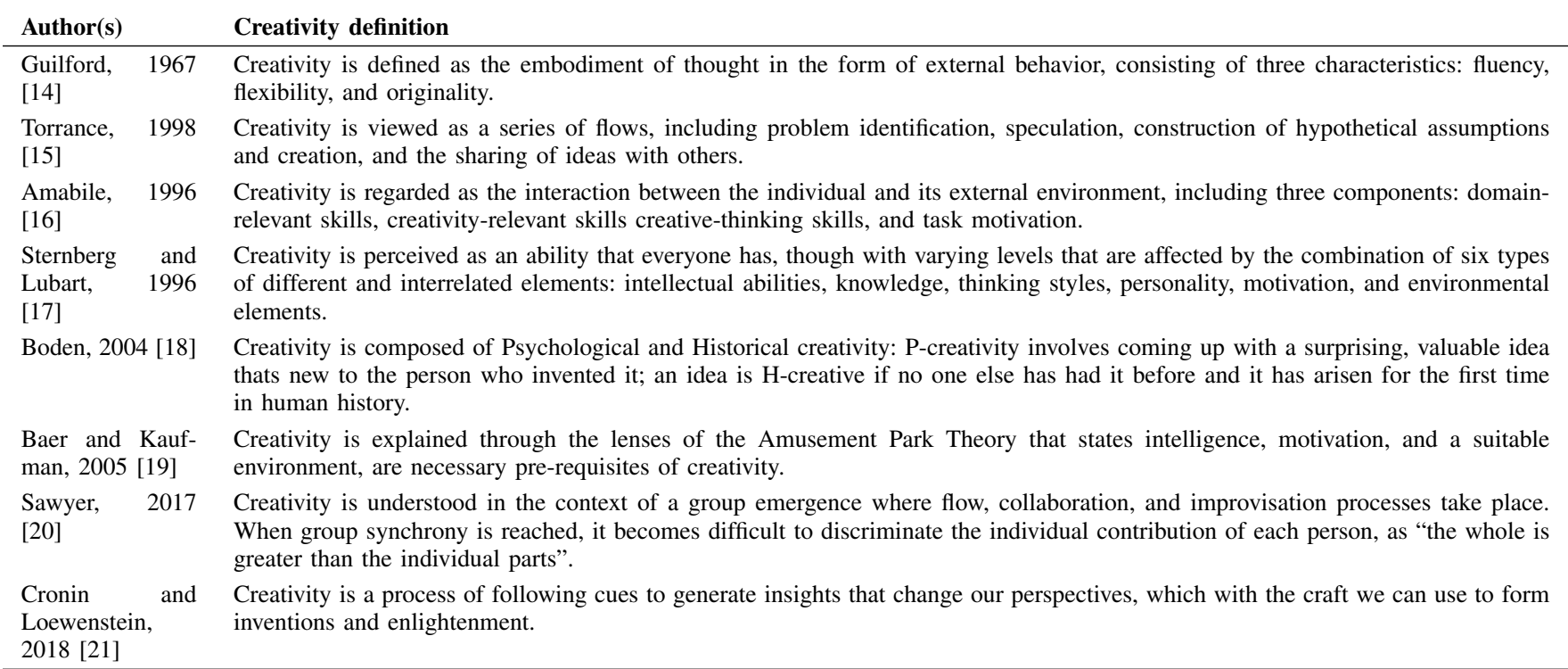

the literature, and an overview of selected creativity definitions can be found in Table I]

Creativity is also composed of different domains, namely figural and verbal. While figural creativity involves creative thinking in visual arts (e.g., drawing, painting, sculpting), verbal creativity relates with communication of ideas and thoughts (e.g., poetry, discourse, and communication) [26]. Creativity is also characterized in terms of the "four P's of creativity", that represent essential cornerstones for creativity research. These four P's are the Person (covers information about personality, intellect, temperament, physique, traits, habits, attitudes, self-concept, value systems, defense mechanisms, and behaviour), Process (relates to motivation, perception, learning, thinking, and communication), Product (when an idea becomes embodied into tangible form), and Press (or environment, and refers to the relationship between human beings and their environment) [27]. In light of these dimensions, different tests and interventions for creative thinking were developed (see a literature review on [28]). For additional material on creativity assessment, see [29]-[32].

Given that the nature of our task consists in a drawing activity, our work focuses on figural creativity. The final drawing is evaluated in terms of creativity, which means we have focused on the study of the creative product, since a creativity score is computed for the final drawing.

\section{B. Collaborative Technology for Creativity}

Technology appears as promising in the field of creativity [33]. Lubart (2005), envisions computers promoting creativity in different ways and has defined fours possible future roles for computers in the field of creativity [34]:

- Computer as nanny - computers encourage creativity by monitoring the working process and supporting the potentially creative person according to the progress made.

- Computer as pen-pal - computers facilitate the exchange of creative ideas between diverse people by integrating and represent them on a physical space.

- Computer as coach - computers can support the creative process by providing information in different ways that people can come up with creative ideas, serving as analogs to jump-start the creative process.

- Computer as colleague - computers work in a real partnership in the creative process with humans, and this is the most ambitious vision of humancomputer interaction.

Computers have already been used to serve as a tool to help game designers to co-design new levels for their games, acting as a colleague, showing a positive influence for the creative level design process [35]. Additionally, when children create a story with autonomous virtual agents in a tablet app, their creative idea generation process is richer with more fluency of ideas, demonstrating that the autonomous behavior of technology can spark creativity in a storytelling task [36]. Other interesting projects with virtual environments have been developed to demonstrate technological creativity, e.g., [37].

Robots have also joined technologies for creativity promotion. A social robot was used to encourage participants to generate creative ideas for their Zen Rock Garden. The results showed that participants engaged in the creativity task for longer periods of time and provided almost twice the number of creative expressions in the robot condition compared to the PowerPoint condition [38]. A different study used a social robot to stimulate curiosity, an essential creative trait, in children. Children's curiosity levels were higher after interacting with the curious and social robot, denoting the impact 

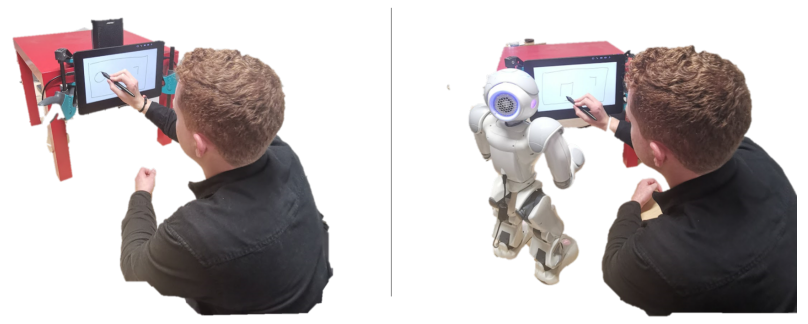

Fig. 1. Experimental study conditions: on the right: participant drawing with a robot; on the left: participant drawing with a tablet.

o robots in humans' creative behavior [39]. Additionally, a robot is being used to stimulate creativity in children during a storytelling task. This robot aims to act as a character in children's stories providing additional ideas for their story plot. Preliminary results were promising in relation with creativity stimulation [40]-[42].

\section{EXPERIMENTAL STUDY: ROBOTS FOR CREATIVITY SPARK}

This work is a design proposal that envisions social robots as drivers for human creativity. To test the hypothesis that robots can play a role in stimulating human creativity, we created a scenario in which a human participant and a robot collaboratively draw something together. This was compared to another study condition in which a participant draw collaboratively with a tablet. For a visual representation of the study conditions, see Figure 1 The drawing task has a collaborative nature because the robot and the human take turns during the drawing process. Additionally, the drawing was open-ended, which means that no specific instruction for a drawing was provided and the task only finishes when the human participant is satisfied with their drawing. The goal was to test if the embodiment and the presence of a robot can stimulate human creativity. It is established in the HRI literature that the mere physical presence of a social robot influences the interaction with the human counterpart [43]-[45], making our research question the following: can the embodiment and the presence of social robot lead to human creativity during a collaborative drawing task? Furthermore, our study hypothesis is that during a collaborative drawing between a human participant and a social robot, figural creativity levels on the human will increase, compared to drawing with a tablet.

\section{A. Participants}

A total of 28 participants were involved in this study, being randomly distributed across two study conditions (robot or tablet conditions). Participants in the tablet condition were 22-30 years old $(M=24.25, S D=2.33), 57.1 \%$ male, and $57.1 \%$ had interacted with a robots before; participants in the robot condition were 19-33 years old $(M=24.35, S D=$ 4.49), $71.4 \%$ male, and $64.3 \%$ had interacted a robots before. Participants were recruited from the Technical University of Lisbon in Portugal, constituting a student academic population. Their participation was voluntary, and each participant signed
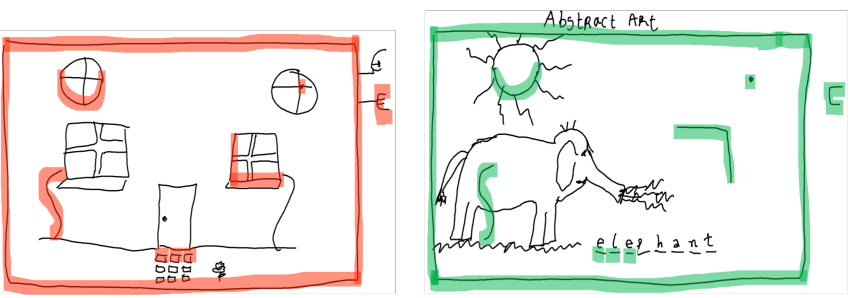

Fig. 2. Examples of final drawings: on the right: drawing made my a participant and a robot. The green aspects of the drawing were the elements drawn by the robot; on the left: drawing made by a participant and the tablet. The red strokes are the elements drawn by the tablet.

a consent form prior to the starting of the study and assented to participate.

\section{B. Creativity Measure}

We used the Test for Creative Thinking-Drawing Production (TCT-DP) test to measure the figural creativity of the human participants. TCT-DP is a well established test in the field of creativity, applicable to persons of a broad age range, is culture-fair, and helps identifying high creative potentials as well as low creative, neglected, and poorly developed ones [46]-[48]. A version of the test adapted to the Portuguese population was used [49].

TCT-DP consists of a sheet of paper with six graphic elements of a circle, a dot, a dashed line, a 90-degree angle, a curved line, and a small open square, placed at fixed and preestablished locations on the page. All of the elements, except for the small open square, are enclosed in a large rectangular frame, and this forms a short of an incomplete drawing. In its traditional form, participants are instructed to "complete the drawing initiated by an artist" and must produce a drawing using these elements. In the case of our study, we changed the instruction and participants were told to "draw something together with the robot", since the this was a collaborative drawing task. In our case, the robot (or the tablet) would draw the already six graphic elements predefined by the creative test and participants would complete the drawing. This ensured that the drawings made by the robot or the tablet across all study sessions were the same, thus, controlling for the creativity stimuli. For an example of how the drawings looked like, see Figure 2. In our study, instead of a sheet of paper used in the traditional application of the TCT-DP, we used a tablet for the drawing task. We opted for this method because the NAO robot (https://www.softbankrobotics.com/emea/en/nao) used for our study lacks dexterity to write. Therefore, a tablet was used to simulate the robot's drawing ability.

The final drawing made by the participants and the robot was scored according to the 14-point scoring system using in general an ordinal measurement scale, proposed by Urban (2005) [47]. A trained psychologist that underwent TCT-DP training scored each drawing. The criteria used to code the drawings are the following: 
1) Continuations (Cn) - number of graphic elements used among the initial elements proposed.

2) Completions $(\mathbf{C m})$ - number of graphic elements used in a meaningful way.

3) New Elements (Ne) - number of new items added to the composition.

4) Connections with lines (Cl) - number of contacts established between the initial graphic elements.

5) Connections made that contribute to a theme $(\mathrm{Cth})$ - degree to which the elements were connected thematically.

6) Boundary-breaking being fragment-dependent (Bdf) - use of the element outside the frame.

7) Boundary-breaking being fragment-independent (Bfi) - use of added elements outside the frame.

8) Perspective (Pe) - use of three-dimensional drawing techniques.

9) Humor, affectivity/emotionality/expressive power of the drawing (Hu) - creation of a humorist or emotional atmosphere.

10) Unconventionality B (Uca) - Unconventional manipulation of the paper. Because we used a tablet for participants to draw that had a fixed location on the table to enable the robot to simulate its drawing, we have excluded this score from our study.

11) Unconventionality B (Ucb) - use of abstract, surrealistic, fictional and/or symbolic themes.

12) Unconventionality $\mathbf{C}$ (Ucc) - use of words, numbers, and/or cartoon-like elements.

13) Unconventionality $\mathbf{C}$ (Ucd) - non-stereotypical utilization of fragments of figures.

14) Speed (Sp) - Time for completion of the drawing. Since we did not limited the time that participants could draw with the robot to avoid imposing many restrictions on this task, we have excluded this score from our study.

\section{Procedure}

Before starting the experiment, participants were asked to read and sign a consent form. After that, the drawing task began and the participant sat in front of the tablet while listening the instructions that the researchers provided, being free to ask any clarification question. The instruction provided to the participants was that they would be "drawing with the robot (or the tablet) something they wished." When everything was clear, the wizard-of-oz (WoZ) started. Both the robot/tablet and the participant had two turns to contribute to the drawing. When the 4 turns were finished, the participant would signal the researchers that the drawing was complete and the experiment finished.

\section{Results}

We analyzed the impact of the robot on the human creativity, by using the non-parametric Mann-Whitney U Test given that our sample followed a non-normal distribution. The between-subject factor was the embodiment (robot or tablet) and the within-subject factor was the score computer for figural creativity. Results reveled no significant result in figural creativity levels for the robot condition (Mean rank $=14.19 ; M=25.57, S D=7.86)$ compared to the tablet condition (Mean rank =17.00; $M=28.29, S D=8.90$ ), $U=$ 91.000, $p=0.400, r=-1.60$. Additionally, we explored two additional dimensions of the TCT-DP introduced by Nogueira (2017), namely conventional and the non-conventional thinkings styles in creativity [50]. The reliability of the items for the non-conventional thinking was poor, $p=0.475$, and questionable for the conventional thinking $p=0.688$. The Mann-Whitney U Test did not reveal statistically significant results in conventional and non conventional thinking, $p>.5$ for the robot (conventional thinking: $M=3.39, S D=1.03$; non-conventional thinking: $M=1.23, S D=0.76$ ) and the tablet conditions (conventional thinking: $3.76 ; S D=0.65$; non-conventional thinking: $M=1.32, S D=1.04$ ).

\section{DISCUSSION}

Creativity is of paramount importance in our current society. With this work, we provided a speculative design study that aims to explore co-creativity tasks between humans and robots. Having robots performing or supporting the creative human process is a way to explore the design of robots for social good. Indeed, creativity is an ability that is desired in developed societies, and that has the potential to be stimulated if trained [28], [51]-[54]. Despite our experiment being one of the first to explore creativity in the field of HRI, we were not able to support our study hypothesis, as no significant improvement in creativity was found when drawing with the robot. Despite of the desire to include interactive technologies in roles that stimulate and foster human abilities, such as of being creative, doing so is not a trivial task. In the case of our work, designing an experiment with a collaborative drawing scenario proposed challenges that need to be addressed in the design perspective. Particularly, the choice of the task can lead to user frustration (e.g., some said the robot "ruined their drawing"), or have higher expectations over robots' abilities (e.g., some participants had higher expectation of the drawing ability of the robot).

The discussion about creativity allow us to reflect on education and on what is taught and how. In this perspective, this project is critical to reflect on traditional learning strategies, the roles in education, and the content being delivered. As we have highlighted in the related work, creativity is not the mere result of learning information, but the use of such information to produce something that can combine previous knowledge to accomplishment something else - from solving problems of different nature, to come up with innovative ideas. Due to this, it is interesting to explore the potential opportunities offered in the exchange and collaboration with robotic partners, which can be an incentive and a guide for the creative process, making it more stimulating and effective. Consequentially, areas of application for exploring scenarios of co-creation with robots can be framed within the notion of robots for social good. In this regard, more investigation should be made using different methodologies for analyzing the process of co- 
creation with robots, namely behavioral analysis of the creative process that can yield exclusive results that are not implicated in the final creative product. Also, variables related with the person, such as the their levels of curiosity and acceptance of robots, should be controlled.

The appearance that a robot should have is another interesting reflection for the design of systems that aims of stimulating creativity, by exploring the role of humanoid robots in contrast to minimalist appearance of robots ${ }^{1}$ Additionally, we should consider diversified contexts, such as school, workplaces and other collaborative settings, as well as long-term multi-party interactions, to explore this topic and learn more about the effective application and use of robots for social good.

\section{ACKNOWLEDGMENTS}

This work was supported by national funds through Fundação para a Ciência e a Tecnologia (FCT) with reference UID/CEC/50021/2019 and by the European Union's Horizon 2020 research and innovation program under grant agreement No 765955 ANIMATAS project. P. Alves-Oliveira acknowledges a FCT PhD grant ref. aASFRH/BD/110223/2015. We thank all the participants of this study for their involvement.

\section{REFERENCES}

[1] H. Gardner and E. Gardner, Art, mind, and brain: A cognitive approach to creativity. Basic Books, 2008.

[2] K. Robinson, Out of our minds: Learning to be creative. John Wiley \& Sons, 2011

[3] P. Collard and J. Looney, "Nurturing creativity in education," European Journal of Education, vol. 49, no. 3, pp. 348-364, 2014.

[4] S. Moran, "The roles of creativity in society," The Cambridge handbook of creativity, pp. 74-90, 2010.

[5] I. N. Dubina, E. G. Carayannis, and D. F. Campbell, "Creativity economy and a crisis of the economy? coevolution of knowledge, innovation, and creativity, and of the knowledge economy and knowledge society," Journal of the Knowledge Economy, vol. 3, no. 1, pp. 1-24, 2012.

[6] D. H. Pink, A whole new mind: Why right-brainers will rule the future. Penguin, 2006.

[7] C. Mellander and R. Florida, "The creative class goes global," in The Creative Class Goes Global. Routledge, 2013, pp. 23-30.

[8] C. A. Burnett and K. P. Haydon, "Do we need a revolutionary approach to bring creativity into education?" in Creative Contradictions in Education. Springer, 2017, pp. 201-220.

[9] T. Davies, "Creative teaching and learning in europe: Promoting a new paradigm," The Curriculum Journal, vol. 17, no. 1, pp. 37-57, 2006.

[10] Ö. Çokpekin and M. P. Knudsen, "Does organizing for creativity really lead to innovation?" Creativity and Innovation Management, vol. 21, no. 3, pp. 304-314, 2012.

[11] J. Kratzer, O. T. A. Leenders, and J. M. v. Engelen, "Stimulating the potential: Creative performance and communication in innovation teams," Creativity and Innovation Management, vol. 13, no. 1, pp. $63-$ 71, 2004.

[12] G. R. Oldham, "Stimulating and supporting creativity in organizations," Managing knowledge for sustained competitive advantage, pp. 243-273, 2003.

[13] J. Dul and C. Ceylan, "Work environments for employee creativity," Ergonomics, vol. 54, no. 1, pp. 12-20, 2011.

[14] J. P. Guilford, "The nature of human intelligence." 1967.

[15] E. P. Torrance, "The nature of creativity as manifest in its testing," The nature of creativity: Contemporary psychological perspectives, vol. 43, 1988.

[16] T. M. Amabile, Creativity in context: Update to the social psychology of creativity. Hachette UK, 1996.

\footnotetext{
${ }^{1}$ See the work of Sougwen Chung on the use of non-humanoid robots for painting exhibitions: http://sougwen.com/
}

[17] R. J. Sternberg and T. I. Lubart, "Investing in creativity." American psychologist, vol. 51, no. 7, p. 677, 1996.

[18] M. A. Boden, The creative mind: Myths and mechanisms. Routledge, 2004.

[19] J. Baer and J. C. Kaufman, "Bridging generality and specificity: The amusement park theoretical (apt) model of creativity," Roeper review, vol. 27, no. 3, pp. 158-163, 2005.

[20] K. Sawyer, Group genius: The creative power of collaboration. Basic Books, 2017.

[21] M. A. Cronin and J. Loewenstein, The Craft of Creativity. Stanford University Press, 2018.

[22] L. W. Anderson, D. R. Krathwohl, P. W. Airasian, K. A. Cruikshank, R. E. Mayer, P. R. Pintrich, J. Raths, and M. C. Wittrock, "A taxonomy for learning, teaching, and assessing: A revision of blooms taxonomy of educational objectives, abridged edition," White Plains, NY: Longman, 2001.

[23] C. W. Taylor, "Various approaches to and definitions of creativity," The nature of creativity, pp. 99-121, 1988.

[24] R. E. Mayer, "22 fifty years of creativity research," Handbook of creativity, vol. 449, 1999.

[25] J. A. Plucker, R. A. Beghetto, and G. T. Dow, "Why isn't creativity more important to educational psychologists? potentials, pitfalls, and future directions in creativity research," Educational psychologist, vol. 39, no. 2, pp. 83-96, 2004

[26] J. P. Guilford, "Creative abilities in the arts." Psychological review, vol. 64, no. 2, p. 110, 1957.

[27] M. Rhodes, "An analysis of creativity," The Phi Delta Kappan, vol. 42, no. 7, pp. 305-310, 1961.

[28] G. Scott, L. E. Leritz, and M. D. Mumford, "The effectiveness of creativity training: A quantitative review," Creativity Research Journal, vol. 16, no. 4, pp. 361-388, 2004.

[29] J. C. Kaufman, J. A. Plucker, and J. Baer, Essentials of creativity assessment. John Wiley \& Sons, 2008, vol. 53.

[30] J. C. Kaufman, Creativity 101. Springer publishing company, 2016

[31] N. K. Park, M. Y. Chun, and J. Lee, "Revisiting individual creativity assessment: Triangulation in subjective and objective assessment methods," Creativity Research Journal, vol. 28, no. 1, pp. 1-10, 2016.

[32] E. P. Torrance, "Predictive validity of the torrance tests of creative thinking," The Journal of creative behavior, vol. 6, no. 4, pp. 236-262, 1972.

[33] J. F. Pedersen, L. M. Vermeulen, C. Remy, M. M. Biskjaer, and P. Dalsgaard, "Mapping the landscape of creativity support tools in hci," in The 2019 ACM CHI Conference on Human Factors in Computing Systems (CHI'19) ACM Conference on Human Factors in Computing Systems. Association for Computing Machinery (ACM), 2019.

[34] T. Lubart, "How can computers be partners in the creative process: classification and commentary on the special issue," International Journal of Human-Computer Studies, vol. 63, no. 4-5, pp. 365-369, 2005.

[35] P. Lucas and C. Martinho, "Stay awhile and listen to 3buddy, a cocreative level design support tool," in Eighth International Conference on Computational Creativity, ICCC, Atlanta, 2017.

[36] A. Pires, P. Alves-Oliveira, P. Arriaga, and C. Martinho, "Cubus: Autonomous embodied characters to stimulate creative idea generation in groups of children," in International Conference on Intelligent Virtual Agents. Springer, 2017, pp. 360-373.

[37] S. Colton, "The painting fool: Stories from building an automated painter," in Computers and creativity. Springer, 2012, pp. 3-38.

[38] P. H. Kahn Jr, T. Kanda, H. Ishiguro, B. T. Gill, S. Shen, J. H. Ruckert, and H. E. Gary, "Human creativity can be facilitated through interacting with a social robot," in The Eleventh ACM/IEEE International Conference on Human Robot Interaction. IEEE Press, 2016, pp. 173180.

[39] G. Gordon, C. Breazeal, and S. Engel, "Can children catch curiosity from a social robot?" in 2015 10th ACM/IEEE International Conference on Human-Robot Interaction (HRI). IEEE, 2015, pp. 91-98.

[40] P. Alves-Oliveira, P. Arriaga, A. Paiva, and G. Hoffman, "Yolo, a robot for creativity: A co-design study with children," in Proceedings of the 2017 Conference on Interaction Design and Children. ACM, 2017, pp. 423-429.

[41] P. Alves-Oliveira, A. Chandak, I. Cloutier, P. Kompella, P. Moegenburg, and A. E. Bastos Pires, "Yolo-a robot that will make your creativity boom," in Companion of the 2018 ACM/IEEE International Conference on Human-Robot Interaction. ACM, 2018, pp. 335-336. 
[42] P. Alves-Oliveira, P. Arriaga, G. Hoffman, and A. Paiva, "Boosting children's creativity through creative interactions with social robots," in 2016 11th ACM/IEEE International Conference on Human-Robot Interaction (HRI). IEEE, 2016, pp. 591-592.

[43] J. Li, "The benefit of being physically present: A survey of experimental works comparing copresent robots, telepresent robots and virtual agents," International Journal of Human-Computer Studies, vol. 77, pp. 23-37, 2015.

[44] Y. Pan and A. Steed, "A comparison of avatar-, video-, and robotmediated interaction on users trust in expertise," Frontiers in Robotics and $A I$, vol. 3, p. 12, 2016

[45] Z. Kasap and N. Magnenat-Thalmann, "Building long-term relationships with virtual and robotic characters: the role of remembering," The Visual Computer, vol. 28, no. 1, pp. 87-97, 2012.

[46] H. G. Jellen and K. K. Urban, "The tct-dp (test for creative thinkingdrawing production): An instrument that can be applied to most age and ability groups." Creative Child \& Adult Quarterly, 1986.

[47] K. K. Urban, "Assessing creativity: The test for creative thinkingdrawing production (tct-dp)." International Education Journal, vol. 6, no. 2, pp. 272-280, 2005.

[48] H. G. Jellen and K. K. Urban, "Assessing creative potential world-wide: The first cross-cultural application of the test for creative thinkingdrawing production (tct-dp)," Gifted Education International, vol. 6, no. 2, pp. 78-86, 1989.

[49] L. Almeida and S. I. Nogueira, "Estudo preliminar do teste test for creative thinking-drawing production (tct-dp)," Psychologica, no. 52-I, pp. 193-210, 2010.

[50] S. I. Nogueira, L. S. Almeida, and T. S. Lima, "Two tracks of thought: A structural model of the test for creative thinking-drawing production (tct-dp)," Creativity Research Journal, vol. 29, no. 2, pp. 206-211, 2017.

[51] R. S. Mansfield, T. V. Busse, and E. J. Krepelka, "The effectiveness of creativity training," Review of Educational Research, vol. 48, no. 4, pp. 517-536, 1978.

[52] L. H. Rose and H.-T. LIN, "A meta-analysis of long-term creativity training programs," The Journal of Creative Behavior, vol. 18, no. 1, pp. 11-22, 1984.

[53] H.-H. Ma, "The effect size of variables associated with creativity: A meta-analysis," Creativity Research Journal, vol. 21, no. 1, pp. 30-42, 2009.

[54] K. Birdi, "Creativity training," in Human Resource Management, Innovation and Performance. Springer, 2016, pp. 298-312. 